\title{
Crystallization Study of $\mathrm{SrTiO}_{3}$ Thin Films
}

\section{Prepared by Dip Coating}

\author{
Edson R. Leite ${ }^{\mathrm{a}}$, Valmor R. Mastelaro ${ }^{\mathrm{b} *}$, Sônia M. Zanetti ${ }^{\mathrm{a}}$, Elson Longo ${ }^{\mathrm{a}}$ \\ ${ }^{a}$ Universidade Federal de São Carlos, Departamento de Química, \\ 13560-905 São Carlos - S.P., Brazil \\ ${ }^{\mathrm{b}}$ Universidade Federal de São Carlos, Departamento de Engenharia de Materiais, \\ 13560-905 São Carlos - S.P., Brazil \\ *e-mail:valmor@if.sc.usp.br
}

Received: February 27, 1998; Revised: March 22, 1999

\begin{abstract}
In this study, the crystallization process of $\mathrm{SrTiO}_{3}$ thin films, prepared by a chemical method, was characterized by Fourier Transformed Infra Red (FT-IR), Grazing Incident X-ray Diffraction (GIXRD), Thermal Analysis (TG) and X-ray Absorption Near Edge Structure (XANES). The results showed that an amorphous inorganic phase is formed, consisting of clusters of oxygen five-coordinate titanium. The amorphous phase begins crystallizing at temperatures above $450{ }^{\circ} \mathrm{C}$. No intermediate crystalline phase and no preferential orientation was observed for films deposited on $\mathrm{MgO}$ (100). FT-IR results suggest the presence of the carbonate group. However, the low thermal stability of this group and the low crystallization temperature of the observed $\mathrm{SrTiO}_{3}$ phase indicate that this carbonate is adsorbed.
\end{abstract}

Keywords: thin films, $\mathrm{SrTiO}_{3}$, characterization

\section{Introduction}

Ferroelectric thin films have been intensively studied due to the intense technological and scientific interest in their potential applications. Among the several thin film processing techniques, chemical methods such as sol-gel and Metalorganic Decomposition (MOD) have received special attention due to the possibility of strict stoichiometric control, the low deposition costs involved (simple deposition methods such as dip and spin coating can be used) and the large substrate area that can be covered. There are, essentially, three different types of sol-gel: colloidal solgel, inorganic polymeric gel derived from organometallic compounds and gel routes involving the formation of organic polymeric glass (polymeric precursor method). The polymeric precursor method, based on the Pechini process ${ }^{1}$, has been successfully used to obtain ceramic powders ${ }^{2-4}$ and ceramic thin films ${ }^{5-7}$.

During the crystallization process of thin films chemically prepared by the polymeric precursor method, an intermediate inorganic amorphous phase is observed after the pyrolysis $\operatorname{step}^{5-7}$. As a consequence, the thin film crystallization process resembles the inorganic glass crystallization process. Recently, Schwartz et al. ${ }^{8}$, using a

* Present address: Universidade de São Paulo, Instituto de Física de São Carlos, Brazil. standard glass nucleation approach, proposed a model in which the degree of orientation and microstructure of thin films prepared by MOD are correlated with the thermodynamic barrier to nucleation. They showed that a change in the crystallization driving force results in a microstructural modification due to the variation that occurs in the barrier heights for interface (film/substrate) and surface nucleation. In another recent paper, Gust et al. ${ }^{9}$ showed that $\mathrm{BaTiO}_{3}$ thin films prepared by sol-gel present an intermediate phase, presumably $\mathrm{BaTiO}_{2} \cdot \mathrm{CO}_{3}$, that is subsequently transformed into $\mathrm{BaTiO}_{3}$. Random nucleation in the film was observed for different substrates.

G. Braunstein et al. ${ }^{10}$ studied the crystallization of $\mathrm{SrTiO}_{3}$ thin films prepared by $\mathrm{MOD}^{10}$. They observed an intermediate crystalline carbonate phase and suggested that this phase delays crystallization and promotes a random nucleation process.

The objective of this work was to study the crystallization of $\mathrm{SrTiO}_{3}$ thin films prepared by the polymeric precursor method. Preliminary studies ${ }^{7}$ have shown that the $\mathrm{SrTiO}_{3}$ phase crystallizes from an inorganic amorphous phase, with no crystalline intermediate phase, as observed during the powder synthesis ${ }^{3}$. Thus, this perovskite oxide might be a suitable material to investigate the crystal- 
lization of thin films prepared by chemical methods. This study may contribute to a better understanding of the crystallization of thin films prepared by sol-gel.

\section{Experimental Procedure}

\subsection{Synthesis and deposition}

The precursor solution was prepared by the dissolution of strontium carbonate in a aqueous titanium citrate solution, prepared from titanium isopropoxide. The molar ratio between titanium and strontium was 1.00 and the citric acid/metal ratio was set at 1.28 (molar ratio). Ethylene glycol was added to the citrate solution to promote polymerization between the titanium citrate and strontium citrate. The citric acid/ethylene glycol ratio was fixed at 40/60 (mass ratio). Figure 1 presents a flow chart for thin film preparation using the polymeric precursor method.

A polymeric solution with a viscosity of $7 \mathrm{mPa} s$ was used for dip coating deposition. Prior to coating, the $\mathrm{MgO}$ (100) substrate was cleaned by immersion in a sulfochromic solution, followed by rinsing several times in deionized water. The dip coating was conducted by immersion of the cleaned $\mathrm{MgO}(100)$ substrate $(1 \mathrm{~cm} \mathrm{x} 1 \mathrm{~cm})$ in the polymeric solution, followed by controlled withdrawal at a speed of $0.7 \mathrm{~cm} / \mathrm{min}$. After deposition, substrates were dried on a hot plate $\left(\sim 150{ }^{\circ} \mathrm{C}\right)$ and heat-treated at $325^{\circ} \mathrm{C}$ for $8 \mathrm{~h}$ in an oxygen flow (pyrolysis step). After pyrolysis, the films were heat treated at different temperatures for $2 \mathrm{~h}$ (crystallization step).

\subsection{Characterization}

Phase evolution was characterized by GIXRD, using $\mathrm{Cu}$ $\mathrm{K} \alpha$ radiation with a grazing incident angle of $\alpha=2^{\circ}$ and $\mathrm{LiF}$ (100) as monochromator, and FT-IR in the transmission mode. The weight loss and pyrolysis behaviors of the gel-derived powders were studied by TG. The microstructure was characterized by transmission electron microscopy (TEM).

Ti K-edge XANES spectra were collected at the LNLS (Laboratório Nacional de Luz Sincrotron, Campinas, Brazil) facility using the EXAFS (Extended X-Ray Absorption Fine Structure) beam station. The LNLS storage ring was operated at $1.36 \mathrm{GeV}$ and $60-100 \mathrm{~mA}$. Data were collected at the Ti K-edge (4966 eV) in the total electron yield mode for thin film samples, and in the transmission mode for powder samples. The beam was monochromatized using a Si (111) channel-cut monochromator and the energy step was equal to $0.5 \mathrm{eV}$. The energy calibration of the monochromator was checked after each spectrum using a $\mathrm{Ti}$ metal foil to provide good energy reproducibility.

Crystalline powder samples were used as structural references: $\mathrm{r}-\mathrm{TiO}_{2}$ (rutile, a commercial powder standard). Solid state reaction was used for $\beta-\mathrm{Ba}_{2} \mathrm{TiO}_{4}: \mathrm{BaCO}_{3}$ and $\mathrm{TiO}_{2}$ were mixed in the stoichiometric amount required for

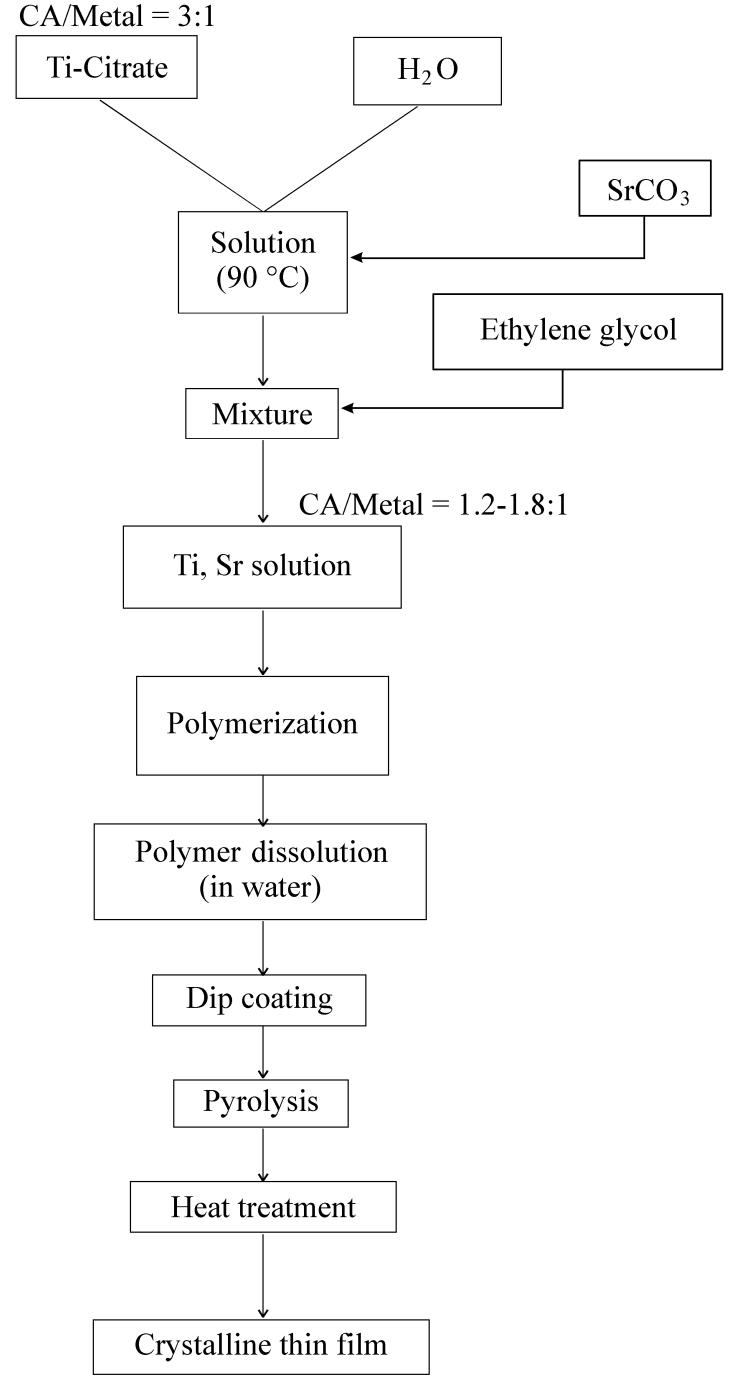

Figure 1. Flow chart for the preparation of $\mathrm{SrTiO}_{3}$ thin film using the polymeric precursor method.

the desired phase and heat-treated at $1100{ }^{\circ} \mathrm{C}$ for $4 \mathrm{~h}$. $\mathrm{Ba}_{2} \mathrm{TiSi}_{2} \mathrm{O}_{8}$ (fresnoite) was obtained from a glassy sample. $\mathrm{SrTiO}_{3}$ were prepared by the polymeric precursor process.

The $\mathrm{Ti}$ atoms present coordination 6 in $\mathrm{r}^{-\mathrm{TiO}_{2}}$ and coordination 4 in $\beta-\mathrm{Ba}_{2} \mathrm{TiO}_{4}$, while they are coordinated by 5 oxygen atoms in $\mathrm{Ba}_{2} \mathrm{TiSi}_{2} \mathrm{O}_{8}$. The XANES experimental data were analyzed using the (XAS) programs of Michalowicz ${ }^{11}$. The XANES spectra were normalized to an edge jump of unity, after removal of the background absorption, by subtraction of a linear function extrapolated from the pre-edge.

\section{Results and Discussion}

\subsection{XANES results}

Figure 2 presents the Ti K-edge XANES spectra of $\mathrm{SrTiO}_{3}$ crystallized thin films compared to $\mathrm{SrTiO}_{3}$ crystallized phase spectra, while Fig. 3 shows the Ti K-edge 
XANES spectra of $\mathrm{SrTiO}_{3}$ crystallized thin films compared to $\mathrm{SrTiO}_{3}$ amorphous thin films. The pre-edge feature of a Ti K-edge XANES spectra located at approximately 4970 $\mathrm{eV}$ are usually attributed to energy level transitions from $\mathrm{Ti}$ 1 s to the Ti3d/O2p molecular orbital ${ }^{12-14}$. Dipole selection rules forbid $1 \mathrm{~s} \rightarrow 3 \mathrm{~d}$ transition (Laporte) but allow this when p-d orbital mixing occurs, as is the case when $\mathrm{Ti}$ is located in a $\mathrm{TiO}_{4}$ tetrahedron or in a $\left.{ }^{[5]} \mathrm{TiO}\right) \mathrm{O}_{4}$ site (i.e., without a center of symmetry ${ }^{14}$. The height and position of the pre-edge feature are direct functions of the degree of $\mathrm{p}-\mathrm{d}$ mixing, site distortion and oxidation state ${ }^{12-14}$.

Qualitative information can be obtained from XANES spectra using model compounds. Farges ${ }^{14}$ made an experimental study of the $1 \mathrm{~s} \rightarrow 3 \mathrm{~d}$ transition as a function of $\mathrm{Ti}$ coordination $\left({ }^{[4]} \mathrm{Ti},{ }^{[5]} \mathrm{Ti}\right.$ and $\left.{ }^{[6]} \mathrm{Ti}\right)$. Based in the $1 \mathrm{~s} \rightarrow 3 \mathrm{~d}$ energy position and normalized height, Farges obtained structural information of Ti atoms in crystalline and glassy fresnoites ${ }^{14}$. Using the information obtained by Farges and comparing the XANES spectra of $\mathrm{SrTiO}_{3}$ compounds presented in Figs. 2 and 3, we were able to obtain qualitative information about $\mathrm{Ti}$ atoms in our samples.

The $1 \mathrm{~s} \rightarrow 3 \mathrm{~d}$ energy position and Ti coordination number for model compounds are presented in Table 1. As can be observed, the position and height of the $1 \mathrm{~s} \rightarrow 3 \mathrm{~d}$ transition depends on the Ti coordination number.

We then compared the $1 \mathrm{~s} \rightarrow 3 \mathrm{~d}$ energy position of $\mathrm{SrTiO}_{3}$ crystallized and amorphous powder samples and the $1 \mathrm{~s} \rightarrow 3 \mathrm{~d}$ energy position of crystallized and amorphous thin films. The position of the $1 \mathrm{~s} \rightarrow 3 \mathrm{~d}$ transition and the Ti coordination number for these four samples are also presented in Table 1. As can be observed, the crystallized thin film presents a similar Ti coordination when compared to the $\mathrm{SrTiO}_{3}$ crystallized powder phase. A mixture of $\mathrm{Ti}$ atoms with coordination five and six was observed for these two samples. However, comparison of the crystallized thin film with the amorphous one showed a significant change

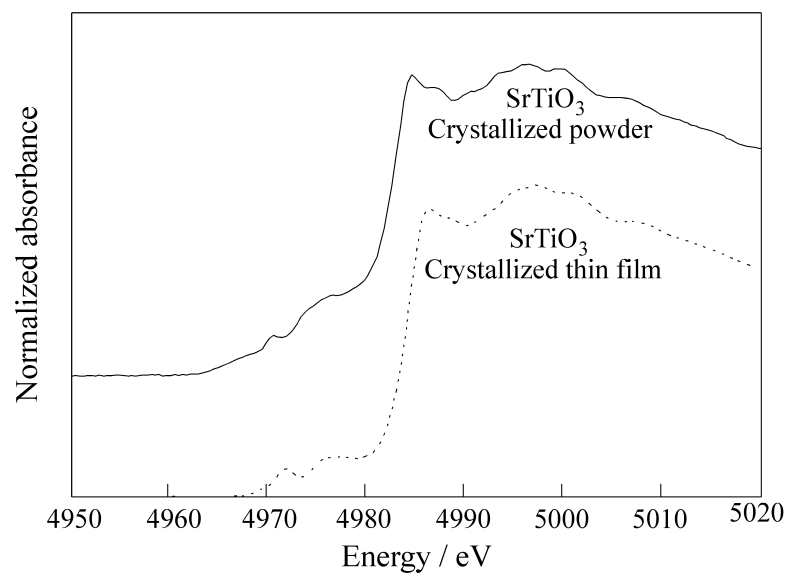

Figure 2. Ti K-edge XANES spectra of $\mathrm{SrTiO}_{3}$ crystallized thin film compared to the $\mathrm{SrTiO}_{3}$ crystallized powder sample.

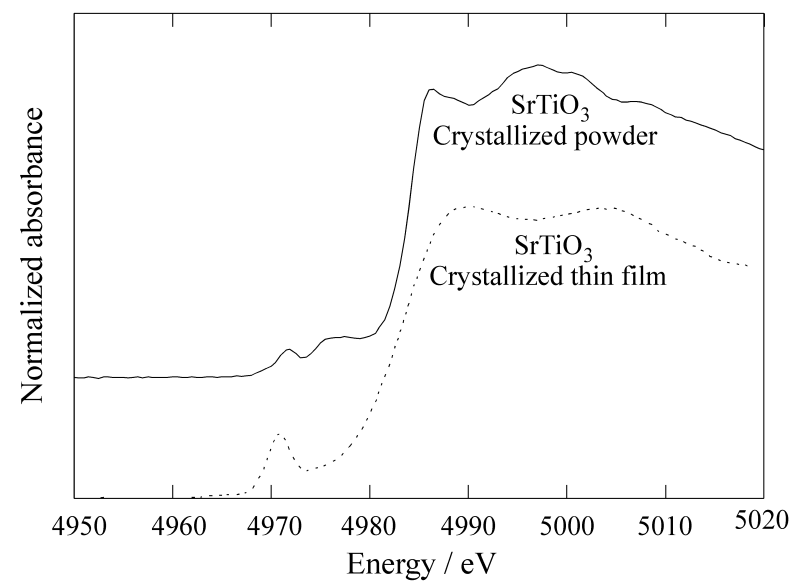

Figure 3. Ti K-edge XANES spectra of $\mathrm{SrTiO}_{3}$ crystallized thin film compared to the $\mathrm{SrTiO}_{3}$ amorphous thin films.

in Ti coordination. In the amorphous thin films most of the Ti atoms presented coordination five, with a small number of $\mathrm{Ti}$ atoms in coordination four and six. These primary results indicate that the coordination of the Ti atoms in the $\mathrm{SrTiO}_{3}$ thin films depends on their physical state, i.e., whether they are crystalline or amorphous.

\subsection{Phase evolution and microstructure}

Figure 4 presents GIXRD patterns of $\mathrm{SrTiO}_{3}$ thin films on $\mathrm{MgO}(100)$ substrate heat treated at different temperatures for $2 \mathrm{~h}$. At $325^{\circ} \mathrm{C}$ a diffuse XRD pattern, related to an amorphous phase, is observed. The film remained in the amorphous state up to $450^{\circ} \mathrm{C}$. TG analysis up to $450{ }^{\circ} \mathrm{C}$ of the polymeric precursor, heat-treated at $325^{\circ} \mathrm{C}$ for $8 \mathrm{~h}$ in an $\mathrm{O}_{2}$ flow, showed no weight loss. This result suggests that the amorphous film, characterized by XANES and GIXRD, consists of an inorganic amorphous phase. At $500{ }^{\circ} \mathrm{C}$ we observed an XRD pattern of crystalline $\mathrm{SrTiO}_{3}$ single phase. No preferential orientation is reported between $500{ }^{\circ} \mathrm{C}$ and $800{ }^{\circ} \mathrm{C}$, which characterizes a polycrystalline thin film. Fig. 5 presents a TEM micrograph of the film heat treated at $600{ }^{\circ} \mathrm{C}$. Well defined grain structure and crack free microstructure are observed. It is worth noting that no

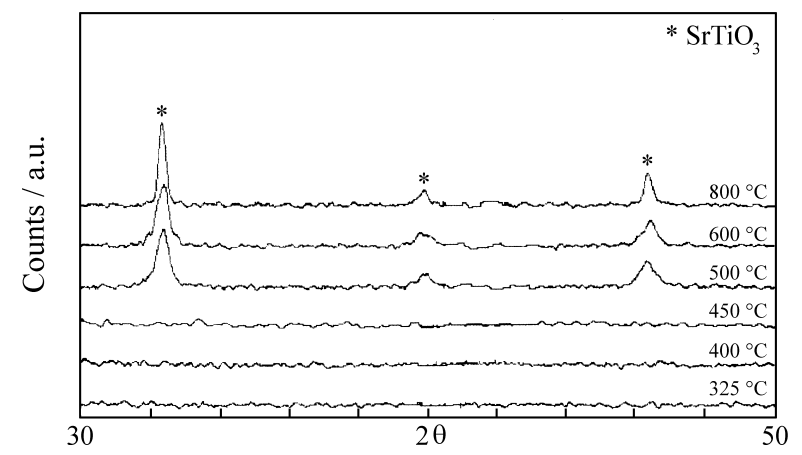

Figure 4. GIXRD patterns of $\mathrm{SrTiO}_{3}$ thin film on $\mathrm{MgO}(100)$ heat treated at different temperatures. 
Table 1. $1 \mathrm{~s} \rightarrow 3 \mathrm{~d}$ transition position and $\mathrm{Ti}$ coordination number for the reference compounds $(*)$ and for the $\mathrm{SrTiO}_{3}$ samples.

\begin{tabular}{|c|c|c|c|c|}
\hline Samples & $1 \mathrm{~s} \rightarrow 3 \mathrm{~d}$ Position $(\mathrm{eV})$ & ${ }^{[4]} \mathrm{Ti}$ & ${ }^{[5]} \mathrm{Ti}$ & ${ }^{[6]} \mathrm{Ti}$ \\
\hline$* \mathrm{Ba}_{2} \mathrm{TiO}_{4}$ & 4969.2 & 100 & - & - \\
\hline$* \mathrm{Ba}_{2} \mathrm{TiSi}_{2} \mathrm{O}_{8}$ & 4970.5 & - & 100 & - \\
\hline$*_{\mathrm{r}-\mathrm{TiO}_{2}}$ & 4971.3 & - & - & 100 \\
\hline $\mathrm{SrTiO}_{3}$ crystallized powder & 4970.8 & 0 & $<40$ & $>60$ \\
\hline $\mathrm{SrTiO}_{3}$ amorphous powder & 4970.1 & $\approx 30$ & $\approx 40$ & $\approx 30$ \\
\hline $\mathrm{SrTiO}_{3}$ crystallized thin films & 4971.0 & 0 & $<30$ & $>60$ \\
\hline $\mathrm{SrTiO}_{3}$ amorphous thin films & 4970.5 & $<10$ & $>90$ & $<10$ \\
\hline
\end{tabular}

intermediate crystalline phase, such as a carbonate phase, was detected by the GIXRD analysis. A carbonate intermediate phase was characterized by XRD during the $\mathrm{SrTiO}_{3}$ powder synthesis using the polymeric precursor method ${ }^{3}$.

Figure 6 presents the FT-IR spectrum of the film heattreated at different temperatures. At $325^{\circ} \mathrm{C}$, only vibrations related to the carboxyl group $\left(\mathrm{COO}^{-}\right)$at 1620,1402 and $1320 \mathrm{~cm}^{-1}$ are observed. At 400 and $450{ }^{\circ} \mathrm{C}$, the vibration at $1620 \mathrm{~cm}^{-1}$ was not observed and the peak intensity at $1402 \mathrm{~cm}^{-1}$ appeared to decrease. A weak broad peak at $1460 \mathrm{~cm}^{-1}$ is observed at these temperatures. The peak at $1460 \mathrm{~cm}^{-1}$ might be related to a carbonate phase $\left(\mathrm{CO}_{3}{ }^{-2}\right.$ group). However, the carbonate phase identified by FT-IR during the $\mathrm{SrTiO}_{3}$ powder synthesis, using the same method, showed a highly accentuated peak at $1450 \mathrm{~cm}^{-13}$. Using FT-IR, Braunstein et al. ${ }^{10}$ observed a carbonate peak at $1425 \mathrm{~cm}^{-1}$ for $\mathrm{SrTiO}_{3}$ thin film prepared by MOD, for samples heat treated at temperatures ranging from 500 to $600{ }^{\circ} \mathrm{C}$. They observed the crystallization of the $\mathrm{SrTiO}_{3}$ phase at temperatures above $700{ }^{\circ} \mathrm{C}$. In our work, the peak at $1460 \mathrm{~cm}^{-1}$ is not observed at temperatures above $450{ }^{\circ} \mathrm{C}$. Hence, the broad peak observed in the amorphous thin film, associated with low thermal stability, is likely related to a non-structural $\mathrm{CO}_{3}^{-2}$ group, i.e., an adsorbed carbonate group.

\subsection{General discussion}

The experimental results showed that, during the crystallization process of $\mathrm{SrTiO}_{3}$ thin films prepared by the polymeric precursor method, an intermediate inorganic amorphous phase was formed after the pyrolysis process. The XANES results showed that the amorphous phase is basically composed of small clusters formed by oxygen five-coordinated $\mathrm{Ti}\left(\left({ }^{[5]} \mathrm{TiO} \mathrm{O}_{4}\right)\right.$. Thus, during the transition from amorphous to crystalline, a significant transformation occurs in the Ti-O clusters, as indicated in reaction (1):

$$
\begin{array}{r}
{ }^{[5]} \mathrm{TiO}^{[\mathrm{O}} \mathrm{O}_{4}\{\text { Amorphous }\} \mathrm{T}>\underset{ }{46]} \mathrm{TiO}_{6}\{\text { Crystal }\}
\end{array}
$$

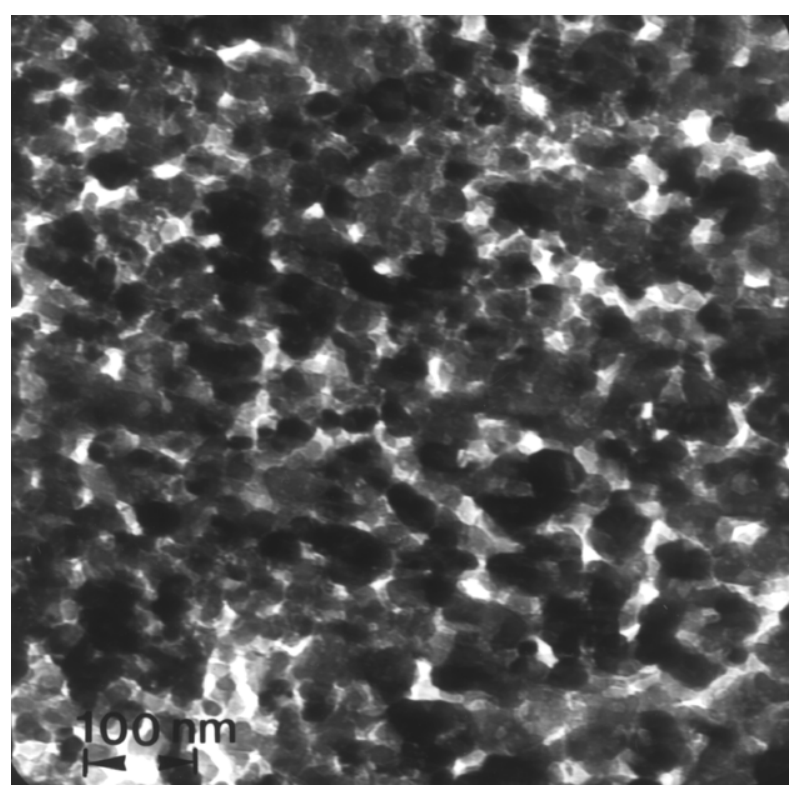

Figure 5. TEM micrograph of the $\mathrm{SrTiO}_{3}$ thin film heat treated at $600{ }^{\circ} \mathrm{C}$, $2 \mathrm{~h}$.

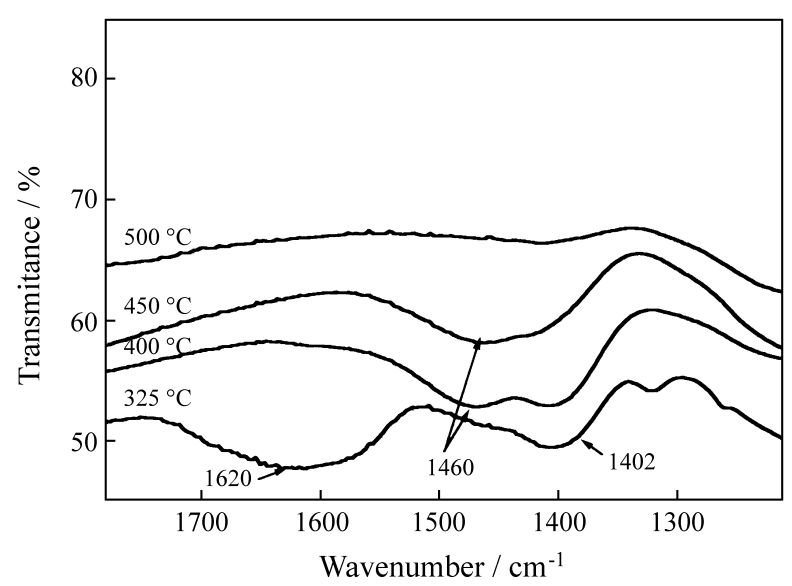

Figure 6. FT-IR spectra of a thin film heat treated at different temperatures.

As described in Eq. 1, the oxygen five-coordinated $\mathrm{Ti}$ in the amorphous state will transform into oxygen six-coordinated $\mathrm{Ti}$ ( $\mathrm{Ti}$ in octahedral position) in the crystalline 
state. Crystallization around $500{ }^{\circ} \mathrm{C}$ is close to the crystallization temperature of $\mathrm{SrTiO}_{3}$ thin films amorphized by ion implantation ${ }^{10}$ or prepared by physical vapor deposition (PVD) ${ }^{16}$. This low temperature crystallization is a strong indication that crystallization occurs directly from the amorphous state, with no intermediate phase involved.

The film remained in the amorphous phase up to $450{ }^{\circ} \mathrm{C}$. The formation of a polycrystalline thin film, for films heat-treated at temperatures above $450{ }^{\circ} \mathrm{C}$, suggests a nucleation process controlled by surface nucleation. This nucleation process will promote crystallization from the surface/film interface towards the film/substrate interface. Thus, no epitaxial growth is observed in the $\mathrm{SrTiO}_{3} / \mathrm{MgO}(100)$ system.

\section{Conclusion}

These experimental results lead to the following conclusions: after the pyrolysis step, an inorganic amorphous phase is formed consisting of small clusters of oxygen five-coordinated $\mathrm{Ti}\left(\left({ }^{[5]} \mathrm{TiO}\right) \mathrm{O}_{4}\right)$; the amorphous phase begins to crystallize at temperatures above $450{ }^{\circ} \mathrm{C}$, with no preferential orientation and with no intermediate crystalline phase; FT-IR results suggest the presence of what is probably an adsorbed carbonate group.

\section{Acknowledgments}

The authors gratefully acknowledge the following Brazilian research financing agencies: FAPESP, CNPqPADCT III, CAPES and PRONEX/FINEP. This research was partially performed at LNLS National Synchrotron Light Laboratory, Brazil.

\section{References}

1.Pechini, M.P. U.S. Patent n. 3,330,697, 1967.
2. Kakihana, M. J. Sol-Gel Sci. Technol., n. 6, p. 7, 1996.

3. Leite, E.R.; Souza, C.M.G.; Longo, E.; Varela, J.A. Ceramic Itern., n. 21, p. 143, 1995.

4. Nobre, M.A.L.; Longo, E.; Leite, E.R.; Varela, J. A. Mater. Lett., n. 28, p. 215, 1996.

5. Bouquet, V.; Leite, E.R.; Longo, E.; Varela, J.A. Key Engineering Materials, v. 132-136, p. 1143, Trans. Tech. Publications, Switzerland, 1997

6. Liu, M.; Wang, D. J. Mater. Research, n. 10, p. 3210, 1995.

7.Zanetti, S.M.; Longo, E.; Varela, J.A.; Leite, E.R. Mater. Lett., n. 31, p. 173, 1997.

8. Schwartz, R.W.; Voigt, J.A.; Tuttle, B.A.; Payne, D.A.; Reichert, T.L.; DaSalla, R.S. J. Mater. Research, n. 2, p. 444, 1993.

9. Gust, M.C.; Evans, N.D.; Momoda, L.A.; Mecartney, M.L. J. Am. Ceram. Soc., n. 80, p. 2828, 1997.

10. Braunstein, G.; Paz-Pujalt, G.R.; Mason, M.G. J. Appl. Phys., n. 73, p. 961, 1993.

11. Michalowicz, A. Logiciels pour la Chimie, Société Française de Chimie, Paris, p. 102, 1991.

12. Waychumas, G.A. Am. Mineral, n. 72, p. 89, 1987.

13. Farges, F.; Brown Jr., G.E.; Rehr, J.J. Geochim. Cosmochim Acta. v. 60, n. 16, p. 3023-3038, 1996.

14. Farges, F. Journal of Non-Cryst. Solids, n. 204, p. 53, 1996.

15. Behrens, P.; Abmann, S.; Felsche, J.; Vetter, S.; Schulz-Ekloff, G.; Jeager, N.I.; Niemann, W. J. Of Chem. Soc. Commun., n. 1990, p. 678, 1990.

16. Hubert, T.; Beck, U.; Kleinke, H. J.Non-Cryst. Sol., n. 196, p. 150, 1996. 